\title{
Identifying reusable services from collaborative activities using activity theory (AT): The Activity-Based Service Identification Framework (ASIF)
}

\author{
Sertse Abebe Ayalew, Hossana Twinomurinzi
}

\begin{abstract}
Service-Orientation (SO) is a paradigm for developing collaboration platforms that promote services as reusable components. Service identification (SI) occurs earlier to identify patterns of a business process (BP) or model that can become software services. Although there exist several SI strategies, most are devised within the context of organizations with mature business processes and formalized structures. There is therefore a need for SI strategies that cater for the emerging heterogeneous and collaborative environments such as exists for small and micro enterprises (SMEs). This paper develops the Activitybased SI Framework (ASIF) from Activity-Theory using design science research (DSR) methods. Six collaboration attributes were elicited for SME; domain-oriented collaboration activity, actions of stakeholders towards the collaboration objective, heterogeneous stakeholders in a problem domain, autonomous actions of a participant, norms(rules) and structures(DOL), and interactive processes of stakeholders during collaboration. The framework is demonstrated using peer-to-peer collaborative lending activities of SMEs in Ethiopia called 'EQUIB'. The findings show that the framework is promising in accurately guiding the identification of reusable and composable services in SME heterogeneous and collaborative contexts.
\end{abstract}

Index Terms - Inter-Enterprise Collaboration, Service-Based Process Design, Service Identification, Business Process Modeling

\section{INTRODUCTION}

$\mathrm{D}$ IGITAL platforms have significantly changed and enhanced the nature of business across many industries [1], [2]. More precisely, collaborative digital platforms are triggering many changes in the SMEs business to move into a collaborative approach [4].

The technical perspective comprehends digital platforms as extensible codebases that implement core functionality, supplemented by modular services [5]. Hence, service orientation $(\mathrm{SO})$ is a development approach in line with digital platforms development since both revolve around the concept of using interoperable and reusable modular components called services [6].

The technical perspective comprehends digital platforms as extensible codebases that implement core functionality, supplemented by modular services [5]. Hence, service orientation $(\mathrm{SO})$ is a development approach in line with digital platforms since both revolve around the concept of using interoperable and reusable modular compo-

- Sertse Abebe Ayalew, Sudan University of Science and Technology, Khartoum, Sudan; Bahir Dar University, Bahir Dar Institute of Technology, Computing Faculty, Bahir Dar, Ethiopia. E-mail: sertse26@gmail.com, Tel: +251-912872503. ORCID-Number: 0000-0002-8940-9464

- Hossana Twibomurinzi, Department of applied Information system, School of Computer Intelligence and Information Systems, University of Johannesburg, South Africa. E-Mail: hossanat@uj.ac.za. Sudan University of Science and Technology, Khartoum, Sudan. ORCID-Number: 0000-00029811-3358 nents called services [6].

The early stage of the $\mathrm{SO}$ development process that identifies candidate service from appropriate sources is known as service identification(SI) [6], [7]. It is also a common task that guides the selection of reusable services during service integration stages [8], [9]. There exist several SI strategies yet most are framed from internal business processes (BPs) [10]. SI strategies are overall not tailored to model collaboration activities of a cluster of heterogeneous organisations, as may be required for dynamic collaboration between SMEs.

SMEs are in a different context from large enterprises to adopt SOA [11]. SMEs have restricted resources, inadequate in-house IT technical expertise, flexible formations, unstable business processes, informal rules \& procedures, and a high level of environmental uncertainty [11], [12]. In these disparate contexts, SMEs have few choices to embrace digital platforms either through interorganizational or community-based collaboration arrangements [11], [13]. Moreover, the collaboration requirements of SMEs are different from the conventional interorganization collaboration. In SMEs, there is a wide range of participants needs, heterogeneity, a growing user base, the constant addition of new requirements, and the individual owner activity domination [15], [16] that call for new approaches.

By considering the peculiarity of SMEs and their collaboration needs; this study proposes ASIF, a new frame- 
work that guides SI tasks from collaboration activities of heterogeneous SMEs using activity theory as a lens and design science research as the methodology.

The remainder of the paper is organized as follows. The next sections present the backgrounds of SI and AT and are followed by the research methodology. The following section presents the design of the ASIF framework. It is followed by a case study that assesses the efficacy of ASIF. The last section presents the conclusions and recommendations.

\section{BACKGROUNDS}

\subsection{Collaboration and SMEs}

Collaboration is an interaction of two or more actors (individual, organization) performing coordinated and synchronized actions to achieve a common goal set by participants [14], [15].

Researchers studied collaboration from different perspectives. Collaboration was conceptualized as a process that has durations and a life-cycle [16]. A collaboration life-cycle that consists of an initiation, formation, operation and decomposition cycle has been proposed by Tellioglu [16].

Collaboration was also conceptualized as an interactive process that comprises cooperation, coordination and communication functions [18], [19]. Ellis [18] has proposed the 3C-model of collaborations using a combined process of communication, cooperation and coordination of users to work together to accomplish a certain goal.

SMEs are the primary solutions to many economic challenges [20], [21] but have many problems because of their small size [22], [23]. To alleviate the challenge of size, SMEs need to collaborate with external partners and one another [24]. The recent trends show several initiations and implementation of a co-creational business model among collaborating startup SMEs [25], [26].

The collaboration process among SMEs has been studied for different purposes. From a collaboration theory perspective, Alonso [27] and Van Hoof [28] have attributed SMEs collaboration by the heterogeneous stakeholders of a problem domain, autonomous participants, interactive processes, norms (rules) and structures, actions of stakeholders towards the collaboration objective, and the domain orientation of action. Besides, this research portrayed the collaboration among SMEs as a process that has its life-cycle and comprises cooperation, coordination and communication functions to work together to accomplish a certain goal.

\subsection{Service Identification (SI)}

SI is a process of eliciting and organizing candidate services from appropriate resources prior to designing software services [6], [7]. SI are differentiated by their purpose [29], directions of analysis, inputs, and outputs [30]. SI strategies may have service-development, application-development, or application-reengineering purposes [29]. Service-development oriented SI strategies identify patterns of independent services to integrate with differ-
TABLE 1

SERVICE TYPE BY DIFFERENT CRITERIA

\begin{tabular}{|c|c|c|}
\hline Criteria & Service type & Description according to [6] \\
\hline \multirow[t]{3}{*}{ Layer } & Application & low-level technical services \\
\hline & Business & $\begin{array}{l}\text { Services that abstract business } \\
\text { processes }\end{array}$ \\
\hline & Process & $\begin{array}{l}\text { Composite services that abstract busi- } \\
\text { ness process logic to coordinated } \\
\text { other services at orchestration level }\end{array}$ \\
\hline \multirow[t]{3}{*}{ Function } & Entity & Abstract of basic data objects \\
\hline & Task & $\begin{array}{l}\text { Abstract functions corresponds to } \\
\text { single-purpose parent business } \\
\text { processes }\end{array}$ \\
\hline & Microservice & $\begin{array}{l}\text { Abstract small portions of task- } \\
\text { services that have unique importance } \\
\text { and reusability potential }\end{array}$ \\
\hline \multirow{3}{*}{$\begin{array}{l}\text { Usage } \\
\text { Context }\end{array}$} & Agnostic & Multi-purpose services that have \\
\hline & & various usage contexts \\
\hline & Non agnostic & Single-purpose service \\
\hline \multirow[t]{2}{*}{ Granularity } & Atomic & $\begin{array}{l}\text { Self-contained service that does not } \\
\text { depend on the state of other services }\end{array}$ \\
\hline & Composite & $\begin{array}{l}\text { A service made of assembly of atomic } \\
\text { or other composite services. }\end{array}$ \\
\hline
\end{tabular}

ent application while application-development-oriented SI strategies aim to select services to compose them as an application within the context of a certain requirements [31]. The latter is usually preceded by an analysis of application requirements [31]. The reengineering-oriented SI strategy aims to modernize existing legacy systems through SO [29].

SI strategies follow a top-down, a bottom-up, or hybrid analysis approach [30], [32], [33] . Top-down SI strategies often work by decomposing business processes or models into smaller components [30]. This kind of SI strategy is preferable when there are no legacy systems. Bottom-up SI strategies analyse existing artefacts to recreate them with SOA [30], [34]. This strategy is often adapted to migrate monolithic systems into SOA. The hybrid approach performs SI tasks by combining the two methods [32], [33], [35].

The inputs that are used by differentiate SI strategies. Bottom-up SI strategies frequently use existing software assets such as source code, user interface, or architecture as inputs [10], [36]. Inputs such as BPs [37], or goals[38], have been used in bottom-up strategies.

Finally SI strategies differ by their output [34]. Outputs of any SI strategies are candidate services and are distinguished by their layer, function [34], and use of extents [6].

\subsection{SI research in the contexts of SMEs Collaboration activity}

Researchers suggested SOA to the design of collaboration systems for SMEs [13]. However, few to no studies on SI strategies have considered the SMEs and their collaboration contexts. To this end, 18 SI strategy research papers published since 2013 has been inquired about their considerations of SMEs situation, collaboration process, and inputs. The evaluation confirmed the lack of SI strat- 


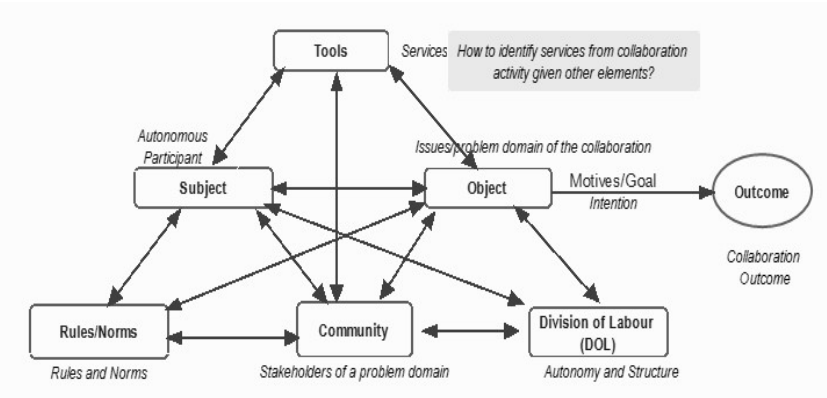

Fig.1 AT representation of collaboration process elements

egies that consider SMEs situations or their collaboration process sufficiently. Only 1 out of 18 studies proposed service identification from interorganizational process design and illustrated the strategy by a collaboration case from sofa-backbone components producer and its accessory suppliers [7]. However, the approach has still focused on stable and departmentalized business processes that are rarely found in most SMEs. Only 4 of the 18 studies considered the collaboration without SMEs contexts. Inputs such as existing system artefact (9 out of 18) and business processes ( 8 out of 18 ) were used dominantly by the SI process. These resources are often not available in most SMEs [12]. Table-2 shows SI strategy research trends.

This study, therefore, adopted AT to understand SMEs and their collaboration through the SME-owner activities so that it guides the SI tasks.

\subsection{AT}

AT is a theoretical framework used to examine different aspects of purposeful human activities [53]. It provides concepts, principles, methods and vocabularies to study human activities [54], [55]. AT represents human activities using an activity system that have seven constituent elements; subject, object, tools, community, norms (rules), division of labour (DOL) and outcomes [56].

1. Subject: It indicates to individuals or collectives actors who perform the activity. This paper used the term actor instead of subject for its familiarity.

2. Object: It attributes to a state of a thing that is the activity's objective.

3. Tools/Artefact: It indicates to the activity's mediator.

4. Community: It refers to the activity's stakeholders. This paper used the term stakeholders instead of community for its familiarity.

5. Norms or Rules: They are the community's rules/norms that govern the activity.

6. Division of Labor: It indicates the community's structure and members role in the activity

7. Outcome: It is the desired state of an object after being transformed by the activity.

\subsection{AT, Collaboration Activity, and SI}

AT has multiple concepts that are useful to study collaboration activity [57] . It presents conceptual and diagram-
TABLE 2

SI STRATEGY RESEARCH TRENDS

\begin{tabular}{llll}
\hline \hline \multirow{2}{*}{ Studies } & \multicolumn{3}{c}{ Contexts considered } \\
\cline { 2 - 4 } & \multicolumn{1}{c}{ A } & \multicolumn{1}{c}{ B } \\
\hline$[39]$ & No & No & Master Data and logical data model \\
{$[40]$} & No & Yes & Process and goal, action-rule \\
{$[41]$} & No & No & Business Process \\
{$[42]$} & No & No & Dependency among Business Process \\
{$[43]$} & No & No & Business Process Repository \\
{$[44]$} & No & No & BPs, goal, and data model \\
{$[45]$} & No & Yes & Partner's interaction, people, machine \\
{$[36]$} & No & No & System Usage \\
{$[46]$} & No & No & Data flow Diagram \\
{$[47]$} & No & No & Source Code \\
{$[48]$} & No & No & Data object Dependency \\
{$[49]$} & No & Yes & Collaborative business Process \\
{$[10]$} & No & No & Source Code \\
{$[50]$} & No & No & Data Flow Diagram \\
{$[37]$} & No & No & Business Processes Models \\
{$[51]$} & No & No & Access Logs \\
{$[52]$} & No & No & Multiple software products \\
{$[7]$} & Yes & Yes & Business Processes, dataflow depend- \\
& & & ency \\
\hline \hline
\end{tabular}

Within context consideration; $A=S M E s, B=$ Collaboration, $C=$ Input used for the SI analysis

matical representations for the collaboration process elements.

The AT has been applied to study interactive processes within collaboration through modeling cooperation, coordination and co-construction interaction levels [58], [59]. The cooperation level models interactions of collaborative actors by focusing on the shared problem and trying to find mutually acceptable ways to conceptualize and solve it [59]. The coordinated level model routine work performed by actors based on their scripted roles or DOL. The co-construction level model processes of redefinition of the cooperation through a joint creation. This level model actors actions based on their DOL in the creation of sequential coherence of the cooperation.

AT have several principles that promote its application in the context of SI problems. The mediation principle affirms tools/artefacts as integral components of human activity and recommends their specification, design, and evaluation be in the context of purposeful activity [56]. This research utilizes the AT to study the specification and evaluation of services from the context of purposeful human collaboration activity. Fig. 1 shows AT representation of collaboration process elements in the context of identifying candidate services roles.

The activity hierarchy principle guides the selection and decomposition of activities into actions and operations through analysis of motives, goals, and contexts. While an activity layer represents motive-oriented collaboration activity, actions are goal-oriented collaborations activity. Operations are referring to collaborations activity performed within a context (condition).

The object-orientation principle presents concepts to study domain-oriented collaboration activities that direct towards the collaboration objectives. It also demonstrates a direction of an actor activity towards the objective [56]. 


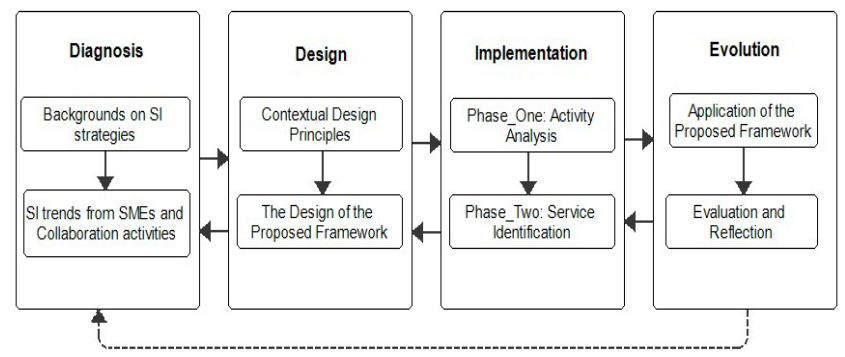

Fig. 2 The elaborated action design research flows adopted from [63]

The internalization/externalization principle helps to capture elements of an actor's operations within collaboration activity. Activity codes and transfer mechanisms determine features of the actor's operation in the contexts of the artifact [56]. Internalization refers to processes that transfer activity codes from artefact to an actor. Externalization refers to processes that transfer activity code from an actor to artefacts [56], [60].

\section{Methodology}

This research adopted an elaborated action design research (EADR) method to guide the creation and design of the proposed artefact. EADR is a problem-driven design science approach [61], [62] that uses independent iterative investigation (problem formulation, artefact creation, evaluation, reflection and learning) activities on top of various design cycles [63]. The EADR cycle consists of diagnosis, design, implementation and evolution stages [63]. The background sections of this manuscript have covered the diagnosis cycle. The background section presented details on service identification, research trends on SI strategies from SMEs and collaboration activity contexts, the AT, and the AT relevance to study collaboration activities and SI strategies. The design cycle presents contextual design principles and elements of ASIF. The implementation cycle demonstrates how elements of ASIF have been implemented in detail. Lastly, the evolution cycle demonstrates the effectiveness and the improvement needed from ASIF through application. Fig. 2 shows the elaborated action design research flows.

The next section draws on EADR into ASIF.

\section{Designing ASIF}

SI strategies are expected both to model environmental contexts and specify services that adhere to the $\mathrm{SO}$ quality principles [6], [45].

Business processes and information systems in most SMEs were immature and volatile to provide approprite input for the SI process. Hence ASIF model SMEs and their collaboration activity through analysis of their owner activity to obtain inputs for the SI analysis. This research elicited contextual design principles that will be embedded in the framework. The next sub-section presents contextual design principles the proposed framework specification.

\subsection{Contextual Design Principles of ASIF}

The following are design principles contextually elicited to ASIF.

1. Guide the selection of the domain-oriented collaboration activity.

2. Guide the decomposition process of a collaboration activity

3. Model actions towards the collaboration objective (goals).

4. Consider the collaboration of heterogeneous stakeholders in a problem domain

5. Consider the autonomous participant collaboration activity

6. Consider norms, rules, and structures (DOL) in collaboration activity to model interactive processes

7. Model interactive processes of stakeholders during collaboration

Moreover, the SO quality principles perspectives, The SI framework should:

8. Support the identification of reusable and composable services

\subsection{ASIF}

ASIF consists of an activity analysis and activitypattern-service mapping phases. The activity analysis phase deals with activity-selection, action-modelling, and operation-modelling sub-phases. The activity selection sub-phase guides the selection of activity domain for the analysis. An action-modelling phase guides the exploration of collaboration actions through hierarchical task analysis method. Operation-modelling is a process of decomposing action into step-by-step automation using the activity context/conditions. The second phase engaged in activity-service mapping processes. It is a process of mapping activity-patterns with service classes. Fig. 3 shows the design of the proposed framework.

\section{IMPLEMENTATION ASIF}

This section presents the detailed implementation of ASIF.

\subsection{Phase One: Activity Analysis}

\subsubsection{Activity Selection}

Activity selection is a process of identifying an activity domain and instantiating it by local contexts. Selecting activity is then initially done by answering questions of "What are collaboration activities with established shared understanding?", " Who are the participants in the activity?", and "Why do they participate?".

Once the activity domain has identified, instantiating local activities from domain activities are the next task of activity selection. The procedure helps to narrow the scope of activity analysis in the context of local problem. The result of activity selection is then a list of activities within the activity domain. 


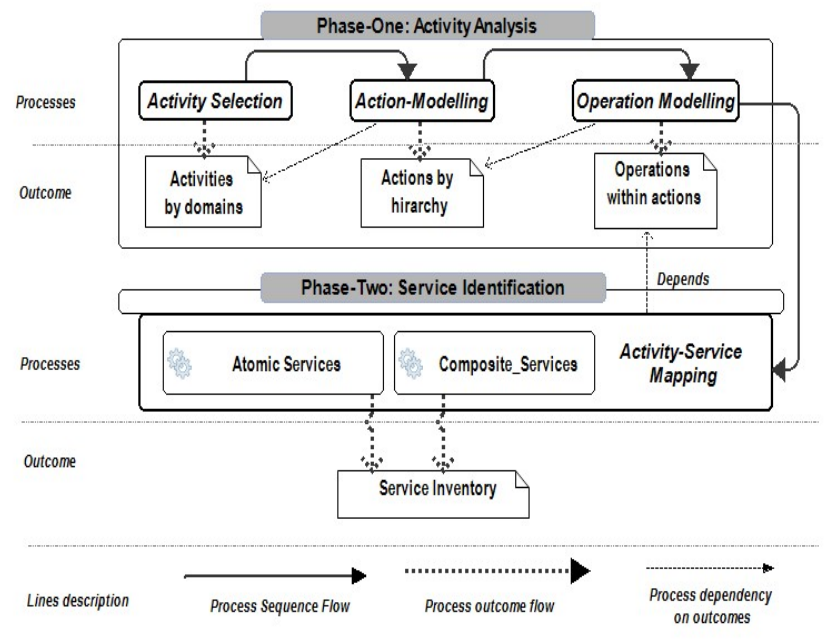

Fig.3 The design of ASIF

\subsubsection{Action Modelling}

Action Modelling is a process of decomposing activity and exploring actions. Decomposing activity is a challenging task since AT has limitations to provide practical methods. However, AT based research often contextually embedded a hierarchical task analysis method for the purpose [64], [65]. This work contextually adapted hierarchical task analysis method for action modeling purposes. The following are steps of an action modeling.

1. Assign the selected collaboration activity domain as the root of the hierarchy.

2. Identify the scope of the collaboration activity. A life cycle of a collaboration activity that comprises the initiation, formation, collaboration, and completion stage [16] defines the scope of activity.

3. Identify sub-actions corresponding to the initiation, formation, collaboration, and completion stages specific goal.

4. Select the first sub-action and assess its state for containing remaining sub-goal to be examined. If the analyzer recognized the sub-action to contain sub-goals

- Identify the overall goal of the selected subaction

- Plan tasks required to achieve the goal. Tasks are logically organized sequences of actions required to achieve a goal [66].

- Identify distinct elements within the task that are associated with intermediate conscious subgoals. Actions are identified concerning their specific orientation to sub-goals to complete a task [66].

- Append distinct elements as sub-actions under the higher level action

Else describe the sub-action as low-level action.

5. Check the next sub-action to be analyzed. The depth-first or breadth-first technique can be ap- plied to traverse among hierarchies of actions. If there is a sub-action repeat step 4 else, end the process.

The output of the action-modelling sub-phase is the action description that shows the hierarchically listed actions and sub-actions within their family in their order of execution.

\subsubsection{Operation Modelling}

Operation Modelling is a process of decomposing actions into operations by eliciting entities, mediators, and collaborative interactions within each sub-action. Entities refer to actor, object and stakeholders descriptions in each action. Mediators mediate interactions among activity entities [67]. Artefacts, DOL and rules are the three forms of mediators of an activity. However, since the objective of this research is to identify services that will be the potential artefacts, rules and DOL are principal mediators. Cooperation, coordination and co-construction (communication) are the three-level of collaborative interaction [59]. The following are the three-stage of modelling collaboration operations.

\section{A. Cooperation Modelling}

Cooperation represents interactions of collective actors (stakeholders) to achieve the goal of the shared object. Modelling cooperation has the following steps.

1. Select each sub-action corresponding to a lowlevel goal.

2. Identify the central shared object of the selected action.

3. Identify stakeholders that have goals towards the shared-object

B. Coordination Modelling

Coordination refers to actors interaction with objects (Actor-Object) based on their scripted roles [59], [67]. Modelling coordination follows the following steps.

1. Describe the DOL among the stakeholder in the selected sub-action

2. Identify sets of distinct actions of each actor based on the actor's scripted role.

3. Identify rules corresponding to each action.

4. Decompose each distinct action into sequences of operations based on rules from a system perspective.

Operation is the step-by-step automation of actions using context or conditions [68]. Hence, operations should be re-described from a system function perspective. The description of an operation shall be done from a computer system prospect through keeping details of activity's entities and methods used by entities to the operation. An operation statement will be described by entity-name, activity-code, and transfer mechanism elements.

C. Model co-construction

Co-construction is a joint creation of the action through interaction by considering the DOL among stakeholder 


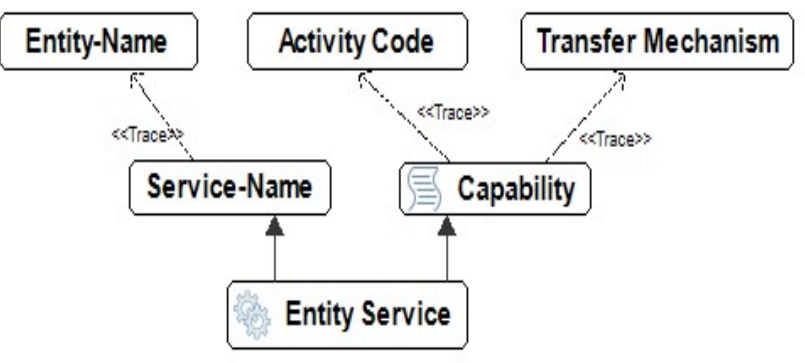

Fig. 4: The proposed framework (ASIF)

members for the creation of sequential coherence of the cooperation [59], [67]. It is the process of describing (actor-object-actor) coordination [68].

1. Identify sets of actors' distinct actions based on their DOL. (done at the coordination level)

2. Identify sequences of actions of each actor that enable them to achieve their individual goal.

3. Identify the initial state and the actor that initiate the co-construction process

4. Identify interactions, rules and assess dependencies and sequences among distinct actions of participant actors based on interaction rules.

5. Identify message exchanges and flows during the re-construction process.

The output of operation-modelling is an operation description that specifies entities (actor, object, and stakeholder), mediators (DOL and rules) and cooperation, coordination, and communication interactions within a lowlevel goal-oriented activity or actions.

\subsection{Phase Two: SI and Service_Organization}

\subsubsection{SI}

SI will be done by mapping information gained from the activity analysis to service classes. The proposed framework helps to identify atomic and composite services.

A. Atomic Service Identification:

ASIF guides atomic entity services (EnSs) and decision services (DeSs) identification.

EnSs identification: An EnS maps distinct entities (actor object. or stakeholder), activity codes and transfer mechanisms associated with the entity. Operation statements decomposed from each actor's distinct action are sources of information. Fig. 4 shows an operation statement entity service mapping.

Moreover, ASIF recommends entity service identification processes to be in an agnostic context. This process helps to model each entity service to be re-usable in different actions of an activity.

DeSs identification: DeS are microservices that abstract the logic of business rules [69]. ASIF guides the mapping of each distinct rule logic as a DeS as per the specification in each discrete action. Moreover, rules that constrained the interactions of two or more actors can be mapped as a DeS.

\section{B. Composite Service Identification}

ASIF guides the identification of composite services corresponding to collaborative_actions and individuals actions. These services are often controller services that manage the effective composition of atomic or other composite services to complete collaborative or individual tasks. In this perspective, ASIF guides the identification of collaborative task_services (CTS), individual's task_services (ITS), and message-service (MeS).

ITS identification: Collaboration is a result of actors' autonomous actions. Hence, the proposed framework promote first the identification of task services corresponding to each distinct actor's action within the collaboration process. The ITSs control the composition of ESs and DeSs corresponding to individual role-oriented actions within the collaboration process.

ITS identify sequences and dependencies among atomic services such as EnSs and DeSs through mapping sequences and dependencies among operations and rules application within each distinct coordinated action of a participant.

MeS identification: MeSs are application services that abstract message exchanges between the collaborating actors during re-construction processes. They are often composite services consists of EnSs and task services as specified by the message task logic. ASIF guides the identification of MeSs through mapping messages exchange patterns among the collaborating actors from the coconstruction model. However, in a general contexts application service layer identification is not viable with activity analysis alone without knowledge and specification of the technology.

CTS identification: CTS are controller services that manage the effective composition of ITSs, MeSs and even some atomic services needed to complete a certain collaborative process. ASIF considers the co-construction model corresponding to a low-level goal-oriented action as the fundamental analysis unit of CTS identification. CTS map collaborative actors' distinct actions, sequences of actions and dependencies among distinct_actions in the reconstruction processes.

\subsubsection{Service organization}

After candidate services are identified, meta-information about services will be profiled in a service_inventory file in a manner that manifests hierarchical order of activity domain, localities of the activity, stages of collaboration life-cycles, actions or sub-actions.

Candidate CTS services will be profiled corresponding to low-level goal oriented-activities or actions. Candidate MeSs will be profiled in the appropriate places where they are usable by CTSs as per the specification of the collaboration activity. Candidate ITS will be profiled based on the role of actors in the appropriate places where they are usable by CTSs. Finally, atomic services such as EnSs and DeS will be profiled corresponding to ITSs where they are usable by ITSs and CTSs. 


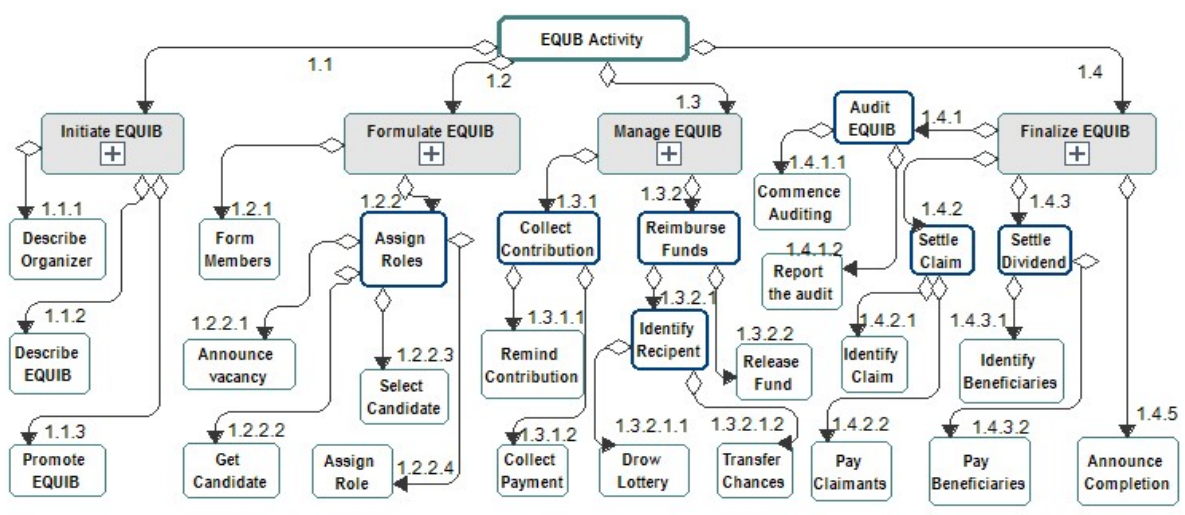

Fig. 5 EQUIB's action model

\section{ASIF APPLICATION}

\subsection{Phase One: EQUIB Activity analysis}

\subsubsection{Activity Selection}

This research selected peer to peer lending collaboration activity as a domain activity for the analysis. This kind of activity is often performed by economic motives of obtaining alternative financial resources [70], [71]. Next, the research has instantiated the peer to peer lending collaboration activity from Ethiopia's SMEs context. The peer to peer lending activity is called EQUIB.

EQUIB is a cultural peer to peer community-based lending activity where participator SMEs contribute a certain fixed amount of weekly or monthly payments for durations equal to the number of members. Each week a member who will take the refund will be identified by a lottery method. To gain a detailed understanding of EQUIB's activity, a case study has been conducted on eleven EQUIBs in Bahir Dar city, Ethiopia.

Qualitative data was collected using semi-structured interviews from organizers, operators and members. Members and organizers, including chairmen, registrar, and the cashiers, were interviewed to gain information about the process of EQUIB-initiation and to understand the EQUIB-collaborative processes.

\subsubsection{EQUIB Action Modelling}

In this sub-phase, hierarchical descriptions of EQUIB activity were identified. The scope of the collaborative activity was defined by its life-cycle consists of the initiation, formation, collaboration, and completion stages. The initial higher-level sub-actions were then are identified corresponding to the collaboration life-cycle stage.

This process identified Initiate-EQUIB, Form-EQUIB, Manage-EQUIB, and Finalize-EQUIB high-level sub action. Later by iterative application of the hierarchical task analysis method, seven intermediate and eighteen lowlevel sub-actions are identified. Fig.5 shows the hierarchically described actions of EQUIB.
TABLE-3

COOPERATION MODEL OF FORM_MEMEBR

\begin{tabular}{llll}
\hline \hline Action-Name & Object & Stakeholders & Goal \\
\hline $\begin{array}{lll}\text { Form EQUIB } \\
\text { Members }\end{array}$ & Membership & $\begin{array}{l}\text { \{Applicants, } \\
\text { Organizer }\}\end{array}$ & $\begin{array}{l}\text { To form EQUIB } \\
\text { Memebers }\end{array}$ \\
\hline \hline \multirow{2}{*}{ COORDINATION OF FORM_MEMBEBR BASED ON DOL } & \multicolumn{2}{c}{ TABLE-4 } \\
\hline \hline Actor & DOL & Coordinated Actions \\
\hline A & Applying for EQUIB & Find EQUIB \\
& membership & Create Application \\
& & Submitt Application \\
& & Sign Membership Agreement \\
B & Approve/reject appli- & Appriase Application \\
& cation & Update Memebr_List \\
\hline \hline
\end{tabular}

Letters refer to actors; $A=$ applicants, $B=$ organizer.

TABLE 5

SAMPLE RULES FOR FORM EQUIB-MEMEBR

\begin{tabular}{ll}
\hline \hline Action & \multicolumn{1}{c}{ Rules } \\
\hline A1 & $\begin{array}{l}\text { Applicant can search for new EQUIBs that has a vacant mem- } \\
\text { bership position }\end{array}$ \\
A2 & $\begin{array}{l}\text { An application form is issued for the applicant if the applicant } \\
\text { live or work in the locality of the EQUIB }\end{array}$ \\
A3 & $\begin{array}{l}\text { Applicants can apply for more than one membership if shares } \\
\text { are available }\end{array}$ \\
A4 & - Applicants shall sign the membership agreement \\
B1 & $\begin{array}{l}\text { Organizer allows only trustworthy applicants to be members of } \\
\text { the EQUIB }\end{array}$ \\
B2 & $-\begin{array}{l}\text { Organizer recognizes the applicant as a member if they sign the } \\
\text { membership agreement }\end{array}$ \\
\hline \hline
\end{tabular}

Letters mixed with numerals refer actors' actions where A refers to applicant and $B$ refers to organizer; $A 1=$ Find $E Q U I B, A 2=$ Prepare Application, $A 3=$ Submitt Apllication, A4=Sign-Membership, B1=Decide on Application, B1=Update-Members

\subsubsection{EQUIB Operation-Modelling}

Operation modelling of $E Q U I B$ collaboration activity was through analysis of the cooperation, re-construction (communication), and coordination interaction among entities (actor, object and, stakeholder) for the twenty low-level actions. 


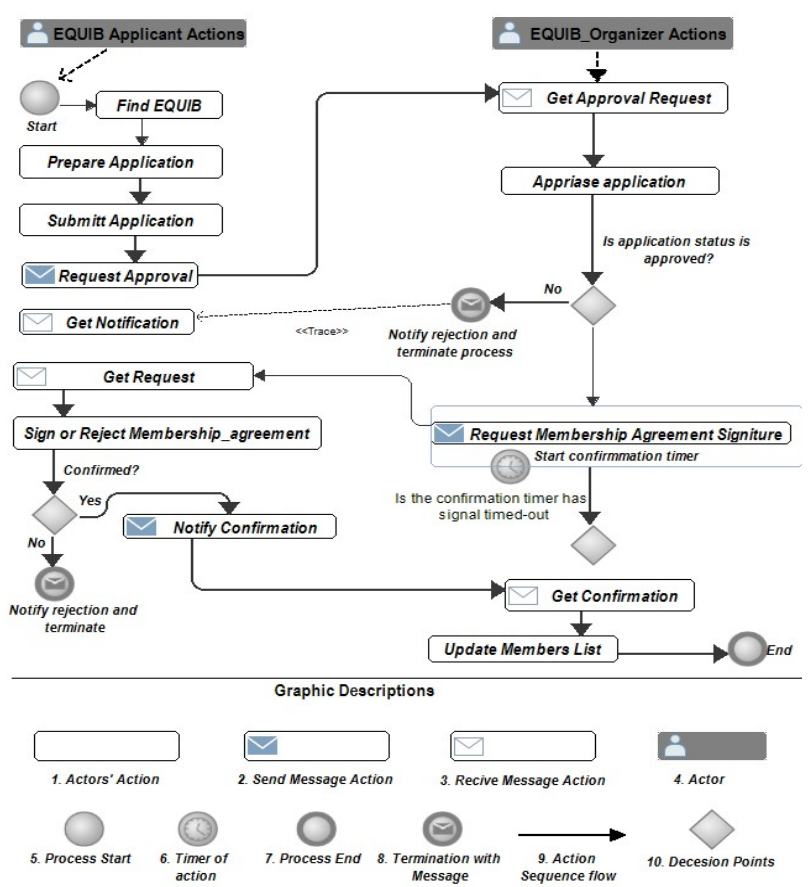

Fig. 6 Form_Member Co-construction Model

A. Cooperation model of EQUIB activity

$E Q U I B$ cooperation model has presented the collective activity of each low-level action by its action-name, shared-object, and stakeholder that have goals towards the shared object. Table-3 shows a sample cooperation model of Form- EQUIB-Member action.

$B$. Coordinated interaction in EQUIB activity

The goal of coordinated interaction is to extract each actor's coordinated actions based on their scripted role. Once coordinated actions of each actor are identified, operations within each distinct action have been redescribed from a system function perspective using the activity rule. Table- 4 and Table- 5 show coordinated actor's actions and rules in connection with each coordinated action within form_Members sub_action.

Table- 6 shows operation statements based on DOL and Rules within form_Members sub_action.

C. Co-construction model of EQUIB

The co-construction interaction has modelleddistinct actions of actors based on their scripted role, interactions of actors, interactions' rules, message flows between actors during the interaction and dependencies and sequences among actions. Fig.6 shows a co-construction model of form-EQUIB-members action.

\subsection{Phase Two: EQUIB Service Identification}

\subsubsection{Atomic_Service Identification}

Entity-Service (ES) Identification: Distinct entities extracted from operation statements have been abstracted as EnSs. Activity codes and transfer mechanisms linked with distinct entities have been mapped with capabilities of EnSs. For instance, operations decomposed from "Find EQUIB", "Prepare application", "Submitt application", and "Sign
TABLE 6

Operation StATEMENTS BASED ON DOL AND RULES FROM SYSTEM PERSPECTIVE

\begin{tabular}{|c|c|}
\hline Action & Operations \\
\hline A1 & $\begin{array}{ll}- & \text { Get the applicant's detail } \\
- & \text { Get EQUIBs history } \\
- & \text { Get registered members' count by EQUIB } \\
- & \text { Verify (registered members count }<\text { allowed member size } \\
& \text { for the EQUIB) } \\
-\quad & \text { If the verification has return false, } \\
- & \text { \{notify Failure, cancel action }\} \\
- & \text { Get EQUIB's details by EQUIB } \\
- & \text { Update applicants' EQUIBs history by applicant and } \\
& \text { EQUIB }\end{array}$ \\
\hline A2 & $\begin{array}{ll}- & \text { Get applicant detail } \\
- & \text { Get applicants' EQUIBs by applicant } \\
- & \text { Get the EQUIB's detail } \\
- & \text { Get address by EQUIB } \\
- & \text { Get address by applicant } \\
- & \text { Verify (applicant-address is similar to EQUIB Address) } \\
- & \text { If the verification has return false, } \\
- & \text { \{notify Failure, cancel action }\} \\
- & \text { Get application form by EQUIB } \\
- & \text { Put application form detail by EQUIB and applicant }\end{array}$ \\
\hline A3 & $\begin{array}{ll}- & \text { Get the applicant detail } \\
- & \text { Get the EQUIB detail } \\
- & \text { Get application form by EQUIB and applicant } \\
- & \text { Get application-form detail } \\
- & \text { Get submit application requests } \\
- & \text { Get Members. count by EQUIB } \\
- & \text { Verify (allowed member size for the EQUIB }>=\text { re- } \\
& \text { quested membership position in the application form }+ \\
& \text { registered members count) } \\
- & \text { If the verification has return false, } \\
- & \text { \{notify Failure, cancel action }\} \\
- & \text { Update application history by applicant and EQUIB }\end{array}$ \\
\hline A4 & $\begin{array}{ll}- & \text { Get the applicant detail } \\
- & \text { Get EQUIBs history by applicant } \\
- & \text { Get the application detail by EQUIB } \\
- & \text { Get agreement form by application } \\
- & \text { Get confirmation options } \\
- & \text { Get confirmation detail } \\
- & \text { Verify (agreement confirmation status }=\text { confirmed) } \\
- & \text { If the verification has return false, } \\
- & \text { \{notify Failure, cancel action }\} \\
- & \text { Update agreement by application }\end{array}$ \\
\hline B1 & $\begin{array}{ll}- & \text { Get organizer detail } \\
- & \text { Get EQUIB by organizer } \\
- & \text { Get applications history by EQUIB } \\
- & \text { Get application detail by application } \\
- & \text { Get confirmation_options } \\
- & \text { Get confirmation } \\
- & \text { Verify (organizer confirmation status for the application } \\
& =\text { confirmed); } \\
- & \text { If the verification has return false, } \\
- & \text { \{notify Failure, cancel action }\} \\
- & \text { Update application approval status by application }\end{array}$ \\
\hline B2 & $\begin{array}{ll}\text { - } & \text { Get organizer detail } \\
\text { - } & \text { Get EQUIBs history by the organizer } \\
\text { - } & \text { Get applications history by EQUIB } \\
\text { - } & \text { Get agreement-signature by application } \\
\text { - } & \text { Get member update requests } \\
\text { - } & \text { Update members. history }\end{array}$ \\
\hline
\end{tabular}

Letters mixed with numerals refer to actors' actions; $A 1=$ Find EQUIB A2= Prepare Application, A3= Submit Application, A4=Sign Membership Agreements, B1=Decide on Application, B1=Update Member Lists.

Membership" actions of an applicant actor indicated by A1, A2, A3, A4, and "Appriase applications" and "Update members list" of an organizer actor indicated by B1, and B2 in table-6 are mapped into eight distinct EnSs. 


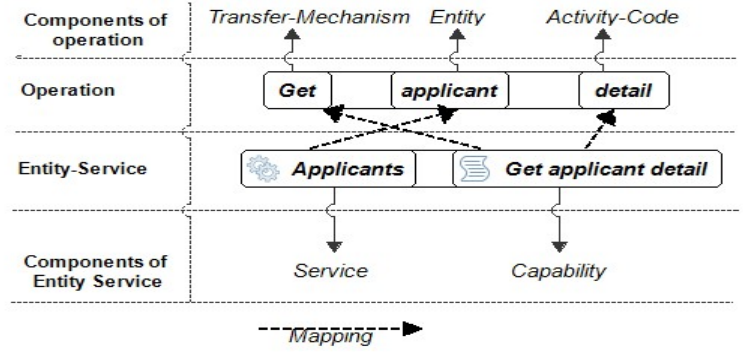

Fig-7 Operation mapping into EQUIB's ENS

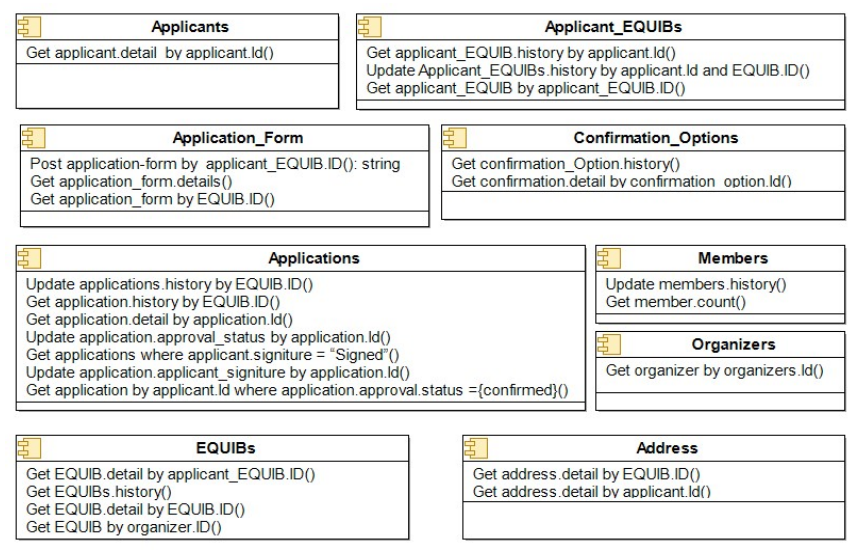

Fig. 8 Candidate ENS from form _Members

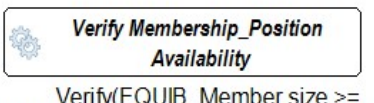

(Application_Form.Number_of_member_Requeasted)+(Member.Count))

Fig. 9 Membership_availability_verifier DeS

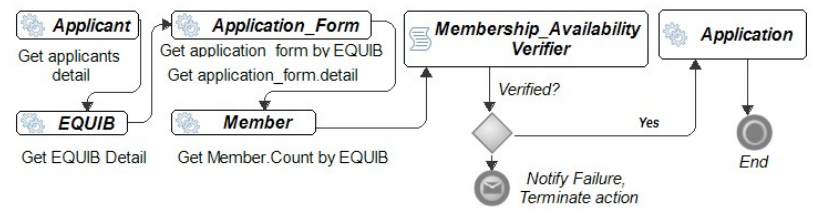

Fig.10 Submitt Application ITS

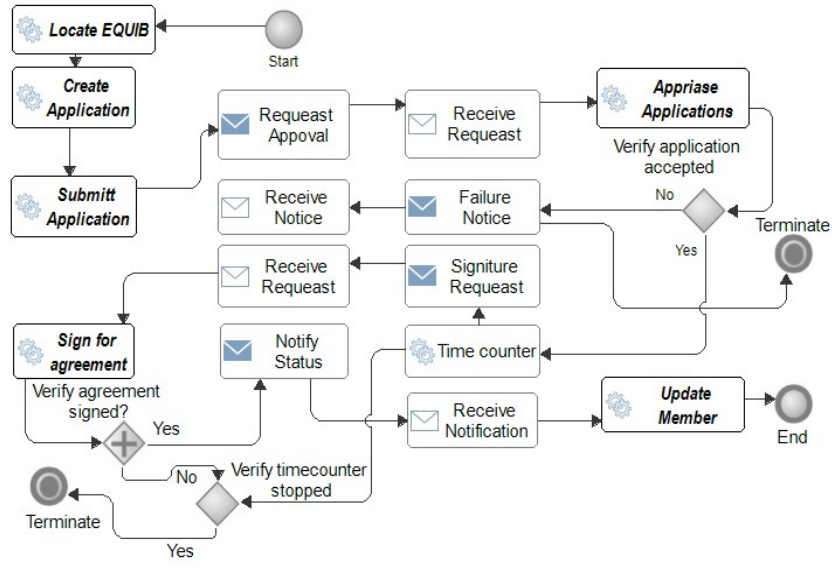

Fig.11 Form Member CTS

From each line of operation, distinct entity, associated activity codes and transfer mechanisms have been elicited and abstracted as an ES. Fig. 7 shows the mapping of an operation statement into an EnS. Fig.8 shows sample candidate EnSs from form_Members sub_action.

A total of twenty-seven reusable EnSs were identified from twenty low-level actions of an EQUIB activity.

EQUIB's DeS Identification: A DeS maps a distinct rule logic connected with distinct actions of each actor. For instance, the "submit-application" action indicated by "A3" in table- 6 contains a rule that enforces the verification of the availability of the membership positions requested by the applicant before creating the application. Thus a logic that verifies the availability of membership positions were abstracted as "Membership_availability_verifier" DeS. Fig.9 shows logics of Membership_availability_verifier DeS. A total of twenty-five DeS are identified for the EQUIB activity.

\subsubsection{Composite Service Idnetification}

EQUIB's ITS identification: ITSs have abstracted each distinct action of actors within a specific collaboration activity based on actor scripted roles. EnSs and DeSs elicited from a given distinct action of an actor are identified as the ingredients of ITS. The sequences and dependencies among EnSs and DeSs have been done through mapping sequences and dependencies among operations and rules within each distinct coordinated action of a participant. Fig. 10 show a model of submit_application ITS.

MeS Identification: MeSs were mapped from message exchanges stories between actors during co-construction processes. For instance, a re-construction process of formMembers action showed in fig. 7 consists of three message exchanges stories. It should be noted that MeS are application services that potentially contain EnS, DeS or task services that need further analysis once the technology for the message exchange has been identified.

CTS identification: CTSs of EQUIB activity were identified corresponding to each low-level action within the activity. The interplays among services within the task service--have been elicited through mapping sequence and dependencies between interacting actors' distinct actions in the re-construction process and mapping sequence and dependencies among operations statements within each discrete action of actors. Fig.11 shows form _member CTS. A total of 20 CTSs has been identified corrosponding to elow-level actions.

\section{Evaluation and Reflection}

The study proposed a framework that guide service identification processes from collaboration activities through the analysis of SME activities. It has two major phases. The activity analysis phase directs the selection and decomposition of domain activities. The service identification phase directs the mapping of activity patterns with service classes.The inquiry evaluated the framework upon the elicited design principles.

The proposed framework allowed the selection and instantiating of domain-oriented collaboration activities. The framework also oversaw the identification of services 
with the functional scope of human's activity domains, motives, and localities.

The framework considered action-modelling processes from contexts of collaboration objects of a stakeholder. A sub-action corresponds to a goal of low-level collaboration object is a unit of activity analysis in the framework. Accordingly, task service identification has targeted the abstraction of the stakeholder's goal-oriented activities within the functional scope of a low-level collaboration object.

The framework considered the collaboration of heterogeneous stakeholders in a problem domain. The framework oversaw operation-modelling processes from contexts of collaborating communities that consist of individuals having distinct goals and roles.

The framework recognised the autonomous participant coordinated separate actions within collaboration activity. Consequently, identification of services mapped both coordinated separate actions of participants and their interactions (cooperation and collaboration) within a lowlevel object-oriented activity.

The framework considered norms, rules, and structures (DOL) of the collaboration activity. It oversaw an operation modelling process by looking at sets of rules and the collaboration task structure. Micro-services identification mapped distinct and reusable business rules. The task service has also mapped the sequences and dependencies among actions of different interacting actors based on their DOL.

The framework considered the interactive processes that could exist among participants collaboration activities. The framework oversaw the cooperation (stakeholder-object), coordination (actor-object), and coconstruction (actor-object-actor) interaction modelling.

Besides, the proposed framework considered the identification of reusable and composable services. Reusability is one of the three $\mathrm{SO}$ quality principles. The proposed framework oversaw the identification of reusable services by modelling entity services from their multipurpose (agnostic) contexts. It is done by abstracting all capabilities of distinct entities to an EnS as it has been specified by operation statements across all low-level actions. For instance, out of twenty-seven reusable entity services, twenty-five of them were reusable across lowlevel actions within the EQUIB activity. Moreover, the framework recommends the abstraction of distinct rule that has re-usability potential in various human activities as a DeS.

The re-composition of services is the final goal of service-oriented computing. Service-composability refers to the capabilities of SI strategies to organize service information in a way it allows easy re-composition of services. The proposed framework oversaw the organization of CTSs be according to the hierarchical family ordering of actions within a life cycle stage and domain activities; ITSs be based on the scripted roles of actors according to their usability by CTSs; MeSs be according to their usability by CTSs; EnSs and DeSs be based on their useability by ITSs or CTSs.

\section{CONCLUSION}

The proposed framework, ASIF, consists of two phases. The activity analysis phase aims to obtain patterns of a collaboration activity through actions and operation modelling processes. The SI phase aims to identify services by mapping activity patterns with service classes. An elaborated action design research method was been adopted for the inquiry. Six core components were elicited as attributes of the proposed framework by considering the SMEs scenario, their collaboration activities.

The evaluation result reveals that the proposed framework is suitable to guide SI processes from collaboration activities of SMEs lived with immature business processes, no pre-established information systems, want to create new collaboration businesses and dependent on individuals' activities.

This research was limited in its consideration of only SMEs contexts and their collaboration activities and therefore can be tested on other similar collaboration contexts.

\section{REFERENCES}

[1] S. Nambisan, D. Siegel, and M. Kenney, "On open innovation, platforms, and entrepreneurship," Strateg. Entrep. J., vol. 12, no. 3, pp. 354-368, 2018.

[2] M. de Reuver, C. Sørensen, R. C. Basole, M. De Reuver, C. Sørensen, and R. C. Basole, "The digital platform: a research agenda," J. Inf. Technol., vol. 33, no. 2, pp. 124-135, 2018, doi: 10.1057/s41265-016-0033-3.

[3] S. Abebe and H. Twinomurinzi, "A Widening Digital Platform Gap: A Systematic Review of the Sharing Economy for Small and Micro Enterprises," in 2019 IEEE AFRICON, 2019, pp. 1-12.

[4] S. Hirata, "An empirical study on value creation of multiproduct small-volume production through industry-academia collaboration," in 2017 IEEE International Conference on Industrial Engineering and Engineering Management (IEEM), 2017, pp. 17381742.

[5] A. Hein et al., "Digital platform ecosystems," Electron. Mark., pp. 1-12, 2019.

[6] T. Erl, Service-oriented architecture: analysis and design for services and microservices. Prentice Hall Press, 2016.

[7] D. Bianchini, C. Cappiello, V. De Antonellis, and B. Pernici, "Service identification in interorganizational process design," IEEE Trans. Serv. Comput., vol. 7, no. 2, pp. 265-278, 2013.

[8] H. Gao, W. Huang, X. Yang, Y. Duan, and Y. Yin, “Toward service selection for workflow reconfiguration: An interfacebased computing solution," Futur. Gener. Comput. Syst., vol. 87, pp. 298-311, 2018.

[9] E. M. Silva, C. Agostinho, and R. Jardim-Goncalves, "A multicriteria decision model for the selection of a more suitable Internet-of-Things device," in 2017 International Conference on Engineering, Technology and Innovation (ICE/ITMC), 2017, pp. 1268-1276.

[10] B. Bani-Ismail and Y. Baghdadi, "Migrating two legacy systems to SOA: a new approach for service selection based on data flow diagram," Int. J. Web Grid Serv., vol. 15, no. 3, pp. 251-281, 
2019.

[11] A. Andriyanto, R. Doss, L. Pan, and P. Yustianto, "A literature review of inter-enterprise SOA in small and medium business communities," in 2018 International Conference on Information Technology Systems and Innovation (ICITSI), 2018, pp. 547-554.

[12] O. Zach, B. E. Munkvold, and D. H. Olsen, "ERP system implementation in SMEs: exploring the influences of the SME context," Enterp. Inf. Syst., vol. 8, no. 2, pp. 309-335, 2014.

[13] A. Andriyanto, R. Doss, and P. Yustianto, "Adopting SOA and Microservices for Inter-enterprise Architecture in SME Communities," in 2019 International Conference on Electrical, Electronics and Information Engineering (ICEEIE), 2019, vol. 6, pp. 282-287.

[14] J. M. McInnerney and T. S. Roberts, "Collaborative and cooperative Learning," in Encyclopedia of Distance Learning, Second Edition, IGI Global, 2009, pp. 319-326.

[15] J. Roschelle and S. D. Teasley, "The construction of shared knowledge in collaborative problem solving," in Computer supported collaborative learning, 1995, pp. 69-97.

[16] H. Tellioglu, "Collaboration life cycle," in 2008 International Symposium on Collaborative Technologies and Systems, 2008, pp. 357-366

[17] X.-L. Chen, A. Mahling, R. Riedel, and E. Müller, “Development of a general collaboration model-Basis for the establishment of a collaboration compass," in 2014 IEEE International Conference on Industrial Engineering and Engineering Management, 2014, pp. 908-912.

[18] C. A. Ellis, S. J. Gibbs, and G. Rein, "Groupware: some issues and experiences," Commun. ACM, vol. 34, no. 1, pp. 39-58, 1991.

[19] H. Fuks, A. Raposo, M. A. Gerosa, M. Pimentel, D. Filippo, and C. Lucena, "Inter-and intra-relationships between communication coordination and cooperation in the scope of the 3C Collaboration Model," in 2008 12th International Conference on Computer Supported Cooperative Work in Design, 2008, pp. 148-153.

[20] H. M. Tahir, N. A. Razak, and F. Rentah, “The contributions of small and medium enterprises (SME's) On Malaysian economic growth: A sectoral analysis," in International Conference on Kansei Engineering \& Emotion Research, 2018, pp. 704-711.

[21] $\square$ tefan C. Gherghina, M. A. Botezatu, A. Hosszu, and L. N. Simionescu, "Small and medium-sized enterprises (SMEs): The engine of economic growth through investments and innovation," Sustainability, vol. 12, no. 1, p. 347, 2020.

[22] F. Eggers, "Masters of disasters? Challenges and opportunities for SMEs in times of crisis," J. Bus. Res., vol. 116, pp. 199-208, 2020.

[23] A. Chandra, J. Paul, and M. Chavan, "Internationalization barriers of SMEs from developing countries: a review and research agenda," Int. J. Entrep. Behav. Res., 2020.

[24] J. Ferreira et al., "Collaborative Production using Dynamic Manufacturing Networks for SME's," IEEE, 2014.

[25] T. R. Eikebrokk, N. F. Garmann-Johnsen, and D. H. Olsen, “Cocreation in networks of SMEs: a conceptual model of the cocreation process," Procedia Comput. Sci., vol. 181, pp. 360-366, 2021.

[26] A. Ghezzi, A. Cavallo, S. Sanasi, and A. Rangone, "Opening up to startup collaborations: open business models and value cocreation in SMEs," Compet. Rev. An Int. Bus. J., 2021.

[27] A. D. Alonso and A. Bressan, "Collaboration among micro and small firms in a traditional industry," J. Small Bus. Entrep., vol.
29, no. 1, pp. 57-75, 2017.

[28] B. Van Hoof and M. Thiell, "Collaboration capacity for sustainable supply chain management: small and mediumsized enterprises in Mexico," J. Clean. Prod., vol. 67, pp. 239-248, 2014.

[29] S. Cai, Y. Liu, and X. Wang, "A survey of service identification strategies," in 2011 IEEE Asia-Pacific Services Computing Conference, 2011, pp. 464-470.

[30] M. Abdellatif et al., "State of the practice in service identification for soa migration in industry," in International Conference on Service-Oriented Computing, 2018, pp. 634-650.

[31] Q. Gu and P. Lago, "Guiding the selection of service-oriented software engineering methodologies," Serv. Oriented Comput. Appl., vol. 5, no. 4, pp. 203-223, 2011.

[32] E. Souza, A. Moreira, and C. De Faveri, "An approach to align business and IT perspectives during the SOA services identification," in 2017 17th International Conference on Computational Science and Its Applications (ICCSA), 2017, pp. 1-7.

[33] B. Bani-Ismail and Y. Baghdadi, "Guiding the selection of service identification methods based on SOA maturity level," Int. J. Web Inf. Syst., 2019.

[34] B. Bani-Ismail and Y. Baghdadi, "A survey of existing evaluation frameworks for service identification methods: towards a comprehensive evaluation framework," in International Conference on Knowledge Management in Organizations, 2018, pp. 191-202.

[35] Z. Dragičević and S. Bošnjak, "Harmonizing Business and Digital Enterprise Strategies Using SOA Middle-Out and Service-Based Approach," 2019.

[36] D. Athanasopoulos, "Usage-Aware Service Identification for Architecture Migration of Object-Oriented Systems to SoA," in International Conference on Database and Expert Systems Applications, 2017, pp. 54-64.

[37] A. Al Shereiqi and Y. Baghdadi, "Business Process Mining for Service Oriented Architecture," in ICT for an Inclusive World, Springer, 2020, pp. 3-19.

[38] J. Li, W. Rong, C. Yin, and Z. Xiong, "Goal-oriented dependency analysis for service identification," Comput. Sci. Inf. Syst., vol. 16, no. 2, pp. 381-407, 2019.

[39] R. S. Huergo, P. F. Pires, and F. C. Delicato, "A method to identify services using master data and artifact-centric modeling approach," in Proceedings of the 29th Annual ACM Symposium on Applied Computing, 2014, pp. 1225-1230.

[40] E. Alirezaei and S. Parsa, "A Hybrid Syntactic and Semantic Approach to Service Identification in Collaborative Networks," in Working Conference on Virtual Enterprises, 2015, pp. 652-659.

[41] M. Dumas and T. Kohlborn, "From business process models to service interfaces," in Handbook on Business Process Management 1, Springer, 2015, pp. 557-578.

[42] J. Li, W. Rong, C. Yin, and Z. Xiong, “Dependency aware business process analysis for service identification," in AsiaPacific Services Computing Conference, 2015, pp. 137-152.

[43] H. Leopold, F. Pittke, and J. Mendling, "Automatic service derivation from business process model repositories via semantic technology," J. Syst. Softw., vol. 108, pp. 134-147, 2015.

[44] M. J. Amiri, S. Parsa, and A. M. Lajevardi, "Multifaceted service identification: process, requirement and data," Comput. Sci. Inf. Syst., vol. 13, no. 2, pp. 335-358, 2016.

[45] O. Sofela, P. de Vrieze, and L. Xu, "Service identification requirements for enteprise information systems," in 2016 10th 
International Conference on Software, Knowledge, Information Management \& Applications (SKIMA), 2016, pp. 454-459.

[46] R. Chen, S. Li, and Z. Li, "From monolith to microservices: A dataflow-driven approach," in 2017 24th Asia-Pacific Software Engineering Conference (APSEC), 2017, pp. 466-475.

[47] A. Furda, C. Fidge, O. Zimmermann, W. Kelly, and A. Barros, "Migrating enterprise legacy source code to microservices: on multitenancy, statefulness, and data consistency," IEEE Softw., vol. 35, no. 3, pp. 63-72, 2017.

[48] M. J. Amiri, “Object-aware identification of microservices,” in 2018 IEEE International Conference on Services Computing (SCC), 2018, pp. 253-256.

[49] R. Blal, A. Leshob, J. Gonzalez-Huerta, H. Mili, and A. Boubaker, "From inter-organizational business process models to service-oriented architecture models," Serv. Oriented Comput. Appl., vol. 12, no. 3, pp. 227-245, 2018.

[50] S. Li et al., "A dataflow-driven approach to identifying microservices from monolithic applications," J. Syst. Softw., vol. 157, p. 110380, 2019.

[51] A. Selmadji, A.-D. Seriai, H. L. Bouziane, R. O. Mahamane, P. Zaragoza, and C. Dony, "From monolithic architecture style to microservice one based on a semi-automatic approach," in 2020 IEEE International Conference on Software Architecture (ICSA), 2020, pp. 157-168.

[52] A. Shatnawi, A. Seriai, H. Sahraoui, T. Ziadi, and A. Seriai, "ReSIde: Reusable service identification from software families," J. Syst. Softw., vol. 170, p. 110748, 2020.

[53] L. C. Yamagata-Lynch, Activity systems analysis methods: Understanding complex learning environments. Springer Science \& Business Media, 2010.

[54] A. B. Anthony and A. B. Anthony, "Activity Theory as a Framework for Investigating District-Classroom System Interactions and Their Influences on Technology Integration," vol. 1523, no. June, 2016, doi: 10.1080/15391523.2012.10782594.

[55] R. Valecha, R. Rao, S. Upadhyaya, and R. Sharman, “An activity theory approach to modeling dispatch-mediated emergency response," J. Assoc. Inf. Syst., vol. 20, no. 1, p. 2, 2019.

[56] Y. Engestrom, "Developmental studies of work as a testbench of activity the ory: the case of primary care medical practice. Understand.," pract, pp. 64-103, 1993.

[57] Y. Wang, L. Huang, and S. vanden Broucke, "An activity theory based approach for ontological modelling of collaborative logistics process dynamics," Int. J. Logist. Res. Appl., vol. 22, no. 4, pp. 371-392, 2019.

[58] D. F. Coskunçay and M. P. Çakir, "Examination of computer supported collaborative business process modeling with activity theory," in Proceedings of the XV International Conference on Human Computer Interaction, 2014, pp. 1-8.

[59] Y. Engeström, K. Brown, L. C. Christopher, and J. Gregory, Coordination, cooperation, and communication in the courts: Expansive transitions in legal work. na, 1997.

[60] L. Winstanley, "Mapping Activity Theory To A Design Thinking Model ( ATDT ): A Framework To Propagate A Culture of Creative Trust .," in International Association of Societies of Design Research Conference 2019, 2019, no. 2007.

[61] A. Tolani, A. Owoseni, and H. Twinomurinzi, "Designing for Context Versus the Lock-in Effect of 'Free'Global Digital Platforms: A Case of SMEs from Nigeria," in International Conference on Design Science Research in Information Systems and Technology, 2020, pp. 321-332.
[62] D. Senshaw and H. Twinomurinzi, "Designing for digital government innovation in resource constrained countries: the case of Woredas in Ethiopia," in International Conference on Design Science Research in Information Systems and Technology, 2020, pp. 42-55.

[63] M. T. Mullarkey and A. R. Hevner, "An elaborated action design research process model," Eur. J. Inf. Syst., vol. 28, no. 1, pp. 6-20, 2019.

[64] H. Huang and G. Gartner, "Using activity theory to identify relevant context parameters," in Location Based Services and TeleCartography II, Springer, 2009, pp. 35-45.

[65] I. T. Wangsa, L. Uden, and S. F. Mills, "Using activity theory to develop requirements analysis framework for collaborative working environments," in Proceedings of the 2011 15th International Conference on Computer Supported Cooperative Work in Design (CSCWD), 2011, pp. 756-763.

[66] P. Cash, B. Hicks, and S. Culley, "Activity Theory as a means for multi-scale analysis of the engineering design process: A protocol study of design in practice," Des. Stud., vol. 38, pp. 132, 2015.

[67] S. Jacoby and E. Ochs, "Co-construction: An introduction." Taylor \& Francis, 1995.

[68] A. Ricci, A. Omicini, and E. Denti, "Activity Theory as a framework for MAS coordination," in International Workshop on Engineering Societies in the Agents World, 2002, pp. 96-110.

[69] X. P. Wang and Y. F. An, "Building flexible SOA-based enterprise process using decision services," in 2010 IEEE 7th International Conference on E-Business Engineering, 2010, pp. 270277.

[70] V. Kumar, A. Lahiri, and O. B. Dogan, “A strategic framework for a profitable business model in the sharing economy," Ind. Mark. Manag., vol. 69, no. August, pp. 147-160, 2018, doi: 10.1016/j.indmarman.2017.08.021.

[71] S. Benoit, T. L. Baker, R. N. Bolton, T. Gruber, and J. Kandampully, "A triadic framework for collaborative consumption ( CC ): Motives, activities and resources \& capabilities of actors," J. Bus. Res., vol. 79, no. November 2016, pp. 219-227, 2017, doi: 10.1016/j.jbusres.2017.05.004.

Sertse Abebe. BSc and MSc in information Science from Addis Ababa University in 2000, 2011 respectively. He is a Lecture at Bahir Dar University; Bahir Dar Institute of Technology, Computing Faculty since 2004. Presented a conference paper entitled "A Widening Digital Platform Gap: A Systematic Review of the Sharing Economy for Small and Micro Enterprises at IEEE AFRICON_2019 Accra, Ghana, Published in IEEEXplore in 2020.

Hossana, Twinomurinz. BSc in Mathematics from Makerere University October 1995, MSc in Information Technology, University of Pretoria September 2005, and University of Pretoria September 2010. Worked at the University of Pretoria, University of South Africa, and currently, He is a C2 South Africa NRF Rated Researcher and Professor with the Department of Applied Information Systems, the University of Johannesburg, College of Business and Economics. He has published 126 articles in conference papers and standard journals. He is a member of the editorial review board for the International Journal of Distributed Systems and Technologies (IJDST) published by IGI global publishing. He is also currently an Associate Editor for the African Journal of Information and Communication. He has previously served as Director for the NEMISA Digital Skills Research Unit, Associate Editor at the African Journal of Information Systems, Chairperson for the ICT4D Flagship at Unisa, and Secretary for SAICSIT. His research interests are in Applied Data Science, Digital Skills, Digital Government, Digital Innovation and ICT for development. He has supervised several Masters and Doctoral students . 